\title{
2. Understanding and promoting adoption of conservation practices by rural landholders ${ }^{1}$
}

\author{
David J. Pannell, Graham R. Marshall, Neil \\ Barr, Allan Curtis, Frank Vanclay and \\ Roger Wilkinson
}

\begin{abstract}
SUMMARY
Research on the adoption of rural innovations is reviewed and interpreted through a cross-disciplinary lens to provide practical guidance for research, extension and policy relating to conservation practices. Adoption of innovations by landholders is presented as a dynamic learning process. Adoption depends on a range of personal, social, cultural and economic factors, as well as on characteristics of the innovation itself. Adoption occurs when the landholder perceives that the innovation in question will enhance the achievement of their personal goals. A range of goals is identifiable among landholders, including economic, social and environmental goals. Innovations are more likely to be adopted when they have a high 'relative advantage' (perceived superiority to the idea or practice that it supersedes), and when they are readily trialable (easy to test and learn about before adoption). Non-adoption or low adoption of a number of conservation practices is readily explicable in terms of their failure to provide a relative advantage (particularly in economic terms) or a range of difficulties that landholders may have in trialing them.
\end{abstract}

\footnotetext{
${ }^{1}$ This chapter is reproduced from Pannell, D.J., Marshall, G.R., Barr, N., Curtis, A., Vanclay, F. and Wilkinson, R. (2006). Understanding and promoting adoption of conservation practices by rural landholders, Australian Journal of Experimental Agriculture 46(11), 1407-1424.
} 


\subsection{INTRODUCTION}

Scientists have been striving to discover and develop new conservation technologies and practices that reduce the extent or the consequences of land and water degradation resulting from extensive agriculture and other rural land uses. Environmental programs like the National Landcare Program, the Natural Heritage Trust and the National Action Plan for Salinity and Water Quality have sought to encourage landholders to adopt these conservation practices, mainly through information provision and social processes, but to some extent, through the payment of financial incentives.

Some conservation practices have been readily and widely adopted by farmers. Most of these primarily address on-farm issues, including lime application to treat acid soils, reduced tillage for reducing erosion and improving soil structure, and, in relevant regions, claying to overcome waterrepellency. In other cases, adoption has been modest at best. For issues like dryland salinity and biodiversity loss, the response by landholders as a whole is clearly insufficient to halt degradation processes.

Some scientists and policy makers have expressed frustration at the observed levels of adoption, and expressed a desire to understand it. We propose that it is understandable based on the large body of literature that considers the adoption of innovations by farmers and other landholders. This paper provides a selective review and interpretation of what is known about the determinants of adoption of new practices by landholders, both conservation practices and other types. The enormous literature on adoption of innovations has previously been reviewed in general (e.g. Rogers 2003) and for agriculture (e.g. Feder and Umali 1993; Ruttan 1996), including in Australian publications (e.g. Guerin and Guerin 1994; Lindner 1987) and in the context of extension (Black 2000). There have been reflective papers outlining lessons from adoption research for the adoption of conservation practices (e.g. Barr and Cary 2000; Cary et al. 2002; Pannell 1999; Vanclay 1992, 1997, 2004) and various studies of the adoption of specific conservation practices in Australian agriculture (e.g. Cary and Wilkinson 1997; Curtis et al. 2000; Kington and Pannell 2003; Lockie et al. 1995; Ransom and Barr 1994; Sinden and King 1990; Vanclay and Lockie 1993).

A feature of the adoption literature is its disciplinary fragmentation. Relevant research is conducted under the banner of economics, sociology, psychology, health promotion, marketing, agricultural extension and anthropology. Despite differences in language and perspective, the general lessons of these different branches of work are broadly consistent and can be readily translated between disciplines. 
This paper is distinguished from past reviews in its aim to present a crossdisciplinary consensus involving authors who come from several disciplinary backgrounds - economics (G. R. Marshall, D. J. Pannell), rural sociology (A. Curtis, F. Vanclay, R. Wilkinson) and psychology (N. Barr) - and who have knowledge of agricultural and environmental issues. This diversity of backgrounds allows us to present and integrate a broader range of perspectives than in previous reviews and overviews. The paper has been written with conscious avoidance of discipline-specific jargon, theories and ideologies in order to allow wide communication and wide applicability.

The intended audience for the paper is broad. The results and implications presented here are relevant to scientists and their funding sources, extension agents and funding bodies, policy makers, managers in government agencies, natural resource management bodies (such as Catchment Management Authorities), non-government conservation organisations and farmer organisations. Extension has been given a particular emphasis in natural resource management programs to date. We define extension broadly to include public and private sector activities relating to technology transfer, education, attitude change, human resource development, and dissemination and collection of information. We emphasise that publicly-funded extension is just one information source among many that landholders use.

We have attempted to relate the review to the perspective of our intended audience, focusing on their concerns about adoption of conservation practices. We imagine that our target audience outlined above has an objective to enhance some conservation outcome(s), and that this would require changes in behaviour by landholders. The question is, what might influence or limit the achievement of such changes? This leads us directly to consider the ways landholders identify and deal with problems and opportunities, so we are fundamentally concerned with landholder perspectives as well, but the primary aim is to translate those perspectives to the other side of the fence.

We have tended to use the more encompassing term 'landholders' rather than 'farmers' as many rural landholders are not farmers. By 'farmers' we mean landholders who use their land to produce food and fibre as a significant share of their family income. Some of the evidence we present may relate specifically to farmers, and where this is so we use the more specific term. As discussed later, non-farm rural landholders differ from farmers in systematic ways, and some important differences in their adoption of conservation behaviours have been observed (e.g. Curtis and Robertson 2003).

The core common theme from several decades of research on technology adoption is that landholder adoption of a conservation practice depends on their expectation that it will allow them to better achieve their goals. If the landholder does not perceive that goals are likely to be met, adoption will 
certainly not follow. Goals vary widely between individual landholders depending on their circumstances and personal preferences, but may include economic, social and environmental outcomes. Adoption is based on subjective perceptions or expectations rather than on objective truth. These perceptions depend on three broad sets of issues: the process of learning and experience, the characteristics and circumstances of the landholder within their social environment, and the characteristics of the practice. These three elements are considered in detail in the following three sections. The last section discusses the implications of the review for various stakeholders: researchers, extension agents, and policy makers.

\subsection{THE PROCESS OF LEARNING AND EXPERIENCE TO INFORM ADOPTION DECISIONS}

Adoption is a learning process with two distinct aspects (Abadi Ghadim and Pannell 1999). One is the collection, integration and evaluation of new information to allow better decisions about the innovation. Early in the process, the landholder's uncertainty about the innovation is high, and the quality of decision making may be low. As the process continues, if it proceeds at all, uncertainty is reduced and better decisions can be made (Marra et al. 2003). At least for relatively simple innovations, a landholder's probability of making a good decision - one that best advances their goals - increases over time with increasing knowledge of, and perhaps experience with, the practice. Viewed in this light, the adoption process is never completed, in the sense of eliminating all uncertainty. All options are continuously open to question and review as new information is obtained or circumstances change.

The other aspect of learning is improvement in the landholder's skills in applying the innovation to their own situation (Abadi Ghadim and Pannell 1999; Tsur et al. 1990). Most farming innovations require a certain level of knowledge and skill for them to be applied in practice, and there can be a wealth of choices in the method of implementation (e.g. timing, sequencing, intensity, scale). Through learning-by-doing, as well as by reading, listening and watching, the necessary skills can be established and enhanced.

This dynamic process has been broken down into stages or phases in a number of different (though similar) ways (e.g. Barr and Cary 2000; Lindner et al. 1982; Pannell 1999; Rogers 2003). One typical description of the sequence follows.

(i) Awareness of the problem or opportunity. In this context, 'awareness' means not just awareness that an innovation exists, but that it is potentially of practical relevance to the landholder. There has been relatively little research on the transition from ignorance to 
awareness. Gibbs et al. (1987) found that the time taken for different farmers in South Australia to become aware of the existence of new innovations varied markedly. For many farmers it amounted to years despite the presence of extension activities designed specifically to raise awareness.

(ii) Non-trial evaluation. Reaching stage (i), the point of awareness, is a trigger that prompts the landholder to begin noting and collecting information about the innovation in order to inform the decision about whether or not to go to the next step of trialing the innovation. Conducting a trial incurs costs of time, energy, finance and land that could be used productively for other purposes. To be willing to trial an innovation, the landholder's perceptions of it must be sufficiently positive to believe that there is a reasonable chance of adopting it in the long run.

(iii) Trial evaluation. Trials contribute substantially to both the decision making and skill development aspects of the learning process. If small-scale trials are not possible or not enlightening for some reason, the chances of widespread adoption are greatly diminished. Landholders will be cautious about leaping to full-scale adoption due to the risk that the innovation will prove a full-scale failure. Untrialable practices may still be adopted (rotary milking platforms are an example), but generally only after substantial informationseeking, discussion, analysis and reflection.

(iv) Adoption. Depending on the trial results, use of the innovation may be scaled up. Typically, adoption is not an all-or-nothing decision there is a grey area between small-scale trialing and the eventual scale of adoption (Duncan 1969). Adoption is often a continuous process, and may occur in a gradual or stepwise manner, sometimes ending in only partial adoption (Wilkinson 1989). Landholders often change and modify the practice or technology to adapt it to their own circumstances. Indeed, such adaptation is often an important outcome of the trialing process.

(v) Review and modification. As noted earlier, in one sense, trialing is never completed, as landholders continue to evaluate the performances of all their practices. However, as the scale of use of an innovation increases, the balance of reasons for using the practice shifts from mainly evaluation to mainly beneficial use. Even after adoption peaks, there is a continuous process of review and modification.

(vi) Non-adoption or disadoption. If external information or local trial results are not sufficiently encouraging (i.e. it appears that the landholder's goals will not be advanced by the innovation), the landholder will reject the innovation. If it is initially adopted but then, 
for example, economic circumstances change or a superior replacement technology or practice becomes available, use of the original innovation may be scaled down and eventually discontinued.

The knowledge that is developed through this process is held by the landholder and is likely to be, to some extent, unique to them. It will probably be based on a mixture of scientific information, personal experience, and cultural influences. Culture includes laws, social norms, ideologies and other human-devised factors that influence behaviour. The culture of landholders is the result of a rich history and it is dynamic, being continually modified by many factors.

The learning process is influenced by the characteristics of individual landholders, their families and broader social environments and by the characteristics of the innovation (see later sections of this paper). Before trialing, the landholder's assessment of a technology or practice relies strongly on information from outsiders. At this stage, social and information networks would be important influences on the decision to proceed to trial, but after trialing has commenced, personal experience gained in that way is likely to be the main influence on further decisions (Dong and Saha 1998; Marsh et al. 2000). This has implications for the role of extension to promote adoption, as discussed later.

There is no guarantee that a landholder's subjective beliefs will ultimately lead them to a final decision that is actually the one most likely to best achieve their goals. Lindner (1987) argued that final adoption decisions are usually correct in the sense that they do actually advance the landholder's goals, but we suggest that some conservation practices are less likely to conform to this generalisation than productivity-related innovations. This may be because some conservation practices are relatively complex or the benefits and costs of some conservation practices are not clearly observable (see the section later on characteristics of conservation practices).

One example of a prominent conservation-related learning failure is provided by Pannell et al. (2001). They noted that many landholders (as well as scientists and policy makers) came to believe that successful prevention of dryland salinity on a farm would generally depend on cooperation from neighbours. Although this is true in some cases, in many it is not. This learning failure would seem to be due to the difficulty of observing the salinisation process, most of which occurs underground with long lags between cause and effect. The point is that even after more than a decade of these farmers using the tools recommended for salinity prevention, their personal experience had not allowed them to converge on an accurate understanding of the impacts of the salinity-management tools. In the absence of readily visible connections between action and response, they were not able to observe the error in what they had previously been led to believe. 
This example highlights that the decision-making process is imperfect. In general, decisions about land management are made without full information. Indeed, there is a trade-off between the costs of acquiring additional information and the benefits of improved decision making, and landholders must strike a balance. Even if full information were available, there are limits to human mental capacity, so people often use heuristics, or 'rules of thumb', to simplify their choices. For example, Ostrom et al. (1994) proposed that individuals faced with problems of collective action involving large groups use heuristics to learn about their complex decision situation. They argued that individuals, lacking both the information and cognitive capacity to calculate all future contingencies in order to select a strategy, adapt their heuristics sequentially as they learn about their situation including about the other people sharing the problem.

In the rest of this paper, we discuss a variety of influences on adoption decisions, but it is noted that because of imperfect decision making and heterogeneity of circumstances, we are always discussing trends and tendencies, rather than deterministic relationships. Factors that enhance the learning process can accelerate the adoption process. These factors may relate to the flows of information between people (e.g. the strength of social networks; see next section) and to characteristics of the innovation itself (e.g. easy observability of trial results; see section after next).

\subsection{SOCIAL, CULTURAL AND PERSONAL INFLUENCES ON ADOPTION DECISIONS}

The previous section was couched in terms of solitary decision making by an individual. Decision making is often also a social process as the decision maker enlists the involvement of others in the decision-making process, or operates as part of a family team. Where a farm is managed by a family (less than $10 \%$ of farms were run by single operators in 2001; Australian Bureau of Agricultural and Resource Economics 2003), the process of decision making is made more complex by the interplay of family members. Although, for convenience, we will often refer to the (singular) landholder or farmer, the reader should bear in mind that for many decisions, particularly larger ones, the decision-making unit can be a team, so that individual perceptions and goals influence a consensus rather than leading directly to a decision.

The significance and complexity of the decision are important factors influencing how widely the information-seeking net is cast and the extent to which decision making is shared. A decision to change to a new herbicide or change wheat variety is likely to be a relatively simple process. A decision 
with potentially significant personal impacts (such as changing farm enterprises) is likely to be a shared decision.

Phillips (1985) found that a typical dairy farmer may embark on anything up to 30 learning projects in one year. A landholder (or landholding family) has limited learning time, and each project must compete with the others for that limited time. A minor decision will receive minimal information time, sufficient to achieve an acceptable solution, which is not necessarily the best possible solution. When contemplating a major change to their farming system, the farmer will often have a hunger for information on the particular issue. The more serious the consequences, the stronger the need for information and for confidence about the outcomes. For more important decisions, the dairy farmers in Phillips' (1985) study sought information from up to 40 people. Weaknesses in the farmer's knowledge were remedied by seeking technical information from people who were seen by the farmer as experts. These could be other farmers, company representatives, stock agents, consultants or researchers. In this initial stage, judgment on the source of information and its credibility is often only cursory. Non-feasible alternatives are rejected, but any option or advice that may be useful is retained (Janis and Mann 1977).

Depending on their personal and family circumstances, the issues about which landholders are most concerned at a particular time may not relate to conservation, or any aspect of land management. A particular landholding family that would at other times welcome information about land conservation practices may have no time or energy for it in the midst of more pressing family issues. Extension activities will at best only reach those landholders who are in a position to be receptive at the time the activities are delivered.

Relative to the information-seeking stage, the next stage, evaluation of the worth of information, is often more socially shared. Information must be assessed against the objectives of the landholder and their family. The goals of landholder families or individuals are heterogeneous, and can include the following: (i) material wealth and financial security; (ii) environmental protection and enhancement (beyond that related to personal financial gain); (iii) social approval and acceptance; (iv) personal integrity and high ethical standards; and (v) balance of work and lifestyle.

Many more specific objectives can be identified, although they generally relate to one or more of the five broad goals outlined above. Makeham and Malcolm (1993) listed the following goals common within the farming community: to survive and grow; to set and overcome challenges; to farm well and be recognised for this; to improve the physical state and appearance of the farm; to acquire extra land or to control a larger business for the future and for heirs; to have a reasonable but not profligate standard of living which compares reasonably with others in farming and society at large; to earn 
enough profit to be able to improve and develop the farm so as not to have to work so hard in old age; to achieve capital gain and increase wealth; to have good quality animals and crops in good condition; to reduce income tax; to have a satisfying rural way of life; to have children well educated; to have enough leisure, increasing over time; to be a respected member of the community; and to have enough money to pursue non-farm interests. Some of these goals are complementary, others are in conflict, so trade-offs are often necessary.

One issue of long-standing discussion and debate has been the relative importance of economic factors as drivers of adoption. The debate started early, with contributions by some of the first researchers in the area (Griliches 1957, 1960; Havens and Rogers 1961). To this day, economists tend to put greater emphasis on the influence of economic factors than do sociologists.

We note that the different views of economists and sociologists sometimes have more to do with language than with substance. For example, from within our own ranks have come papers that describe exactly the same factors as being 'social' (e.g. Vanclay 1986, 1992) and 'economic' (e.g. Pannell 1999). Economists tend to have a broad concept of what constitutes an economic benefit (e.g. including consideration of costs and benefits over the long-term, risk, the cost of foregoing other opportunities, the value of keeping options open, resource degradation, farming-system issues, and nonfinancial benefits and costs). Economists may actually be considering factors that others consider to be non-economic, but interpreting them through an economic prism. In the same way, sociologists have a broad concept of what constitutes a social benefit (Vanclay 2002).

In our judgment, there are several important influences on adoption, and economic benefit (broadly defined) is one of them. Reflecting our combination of economic and social perspectives, when we say 'economic benefit', we mean the net economic benefit as perceived by the landholder, not as calculated by an economist. Often the (perceived) potential financial gain plays an important role (e.g. Cary and Wilkinson 1997), although sometimes it is counterbalanced by concerns over issues such as time, lifestyle or risk. Some farmers place the desire to make more money low on their list of priorities (Hawkins and Watson 1972; Presser and Cornish 1968; Vanclay 2004). For most, making money will not be their core goal, but it will be an important tool for achieving higher order goals such as a secure family lifestyle or keeping the farm property in the family (which means that economic return is still an important influence on their behaviour). Further, even landholders with a low emphasis on generating additional cash income are unlikely to be attracted to adoption of practices that would involve large economic losses (e.g. removal of woody weeds in some situations). 
When an adoption decision has a potential to threaten the higher order goals, the process of decision making is much more likely to be socially shared. Dealing with risky decisions with important consequences is a stressful experience for most people. Most decision makers cope with the stress of uncertainty by seeking both further information and social or family support for decision making, particularly in the non-trial evaluation phase. The issues will not only be 'will this work?' but also 'will these people share responsibility for the decision?', and 'will they support me if it fails?'

The more difficult the decision, the more the decision maker will engage and re-engage with their personal support network and with other sources of information. The major decision will be often be preceded by a series of smaller decisions to continue investing time, effort, and sometimes money, in continuing the decision evaluation. At each of these subsidiary decision points, the decision maker (or members of the decision-making team) may seek the advice and support of close contacts (Phillips 1985). Later in the process, social commitment and support will help maintain confidence in the uncertain stages of trialing and early adoption. Peer expectations of continued commitment or personal support and encouragement will reinforce commitment and provide a buffer against setbacks (Janis and Mann 1977).

When adoption is viewed as a social process, it becomes clear that one should expect adoption behaviour to be influenced by the personality of the decision maker, their social networks, personal circumstances and family situation. It seems that in the empirical literature every measurable characteristic of farms and farmers has been found to be statistically related to some measure of adoption of some innovation (e.g. Rogers 2003). This reflects the heterogeneity of adoption study settings, the very large size of the literature, and the variable quality of empirical studies (as noted, for example, by Lindner 1987; Vanclay 1986). Vanclay (1986) particularly criticised the statistical analyses in many studies for failing to properly untangle the effects of multiple causal variables.

Personality may play a major part in the style of decision making used by landholders, although, because of measurement complexity, it has rarely been studied. One important personality trait is 'locus of control'. Individuals with a strong belief in their own ability to influence the circumstances of their lives are described as having an 'internal locus of control'. Persons with this personality trait are likely to experience less stress in decision making. The individual portrayed in John O'Brien's famous Australian poem 'Said Hanrahan' no doubt had an external locus of control ('If we don't get three inches, man, or four to break this drought, we'll all be rooned,' said Hanrahan, 'before the year is out') and may have been more troubled by stress during decision making. The limited research into farmer stress in Australia has shown that financial difficulty alone does not predict stress. Stress instead results from a combination of circumstances and the 
interpretation placed upon those circumstances by the individual. There is great variation in psychological propensity towards the experience of stress (Cary and Weston 1978; Weston and Cary 1979).

Economists study 'risk aversion', which is perhaps akin to a personality trait. Risk aversion describes an individual's tendency to take or avoid risks in their decision making. Empirical evidence indicates that farmers vary widely in their personal degree of risk aversion (Abadi Ghadim and Pannell 2003; Bardsley and Harris 1987; Bond and Wonder 1980). The more riskaverse a landholder is, the greater will be his or her tendency to adopt an innovation that is perceived to reduce risk (e.g. Shapiro et al. 1992) or to not adopt an innovation that is perceived to increase risk (e.g. Abadi Ghadim $e t$ al. 2005).

Another important personality trait is introversion extroversion. Shrapnel and Davie (2001) and Shrapnel (2002) examined the personality profile of a sample of Queensland graziers. Of 14 general personality styles expected in the wider community, graziers were found to generally fall into a limited suite of five styles. 'Our findings indicate that they are indeed a special breed, with characteristic[s] that set them apart from members of an urban community' (Shrapnel and Davie 2001, p. 177). These characteristics include a tendency to introversion and discomfort within group situations. Although this work is formative, it provides an indication of why one-on-one relationships are likely to be preferred by many farmers over group settings in the evaluation of options for important decisions. This personality trait will influence the extent and nature of a farmer's personal networks. Personal networks are an important influence on adoption behaviour and are increasingly important as a medium for the implementation of government and industry programs.

A widely discussed and long-standing concept is categorisation of people across a spectrum from innovators to laggards, presented with little change from Rogers (1962, pp. 168-171) to Rogers (2003, pp. 282-285). People do indeed have personal characteristics that influence their adoption decisions fairly consistently. However, the concept of adopter categories suggests that innovativeness is a personal characteristic that people apply equally to every adoption decision that they make. This is not so. People who adopt one innovation early are not necessarily early adopters of all innovations. It may be that the innovation in question is particularly attractive in their individual circumstances, whereas the same decision maker when considering a different innovation that is less attractive to them than to others may behave as a slow adopter or non-adopter.

Several aspects of the linkages between landholders and others may affect the adoption decision:

(i) The existence and strength of landholders' social networks and local organisations (e.g. Sobels et al. 2001) and membership of 
organisations such as catchment groups have been shown to be positively related to adoption (e.g. Kington and Pannell 2003). A number of studies have found a positive relationship between membership of Landcare groups and adoption of some conservation practices (Cary et al. 2002; Curtis 1997; Curtis and De Lacy 1996; Mues et al. 1998), although the direction of causality is not clearly established.

(ii) The physical proximity of other adopters is positively related to adoption (e.g. D’Emden et al. 2006; Hagerstrand 1967; Ruttan 1996).

(iii) The physical distance of the property from sources of information about the innovation is important - more distant landholders are less likely to adopt, perhaps because the information appears less relevant to them than to those who are close to the information source, or perhaps because they receive less exposure to the information (e.g. Lindner et al. 1982).

(iv) A history of respectful relationships between landholders and advocates for the innovation, including scientists, extension agents, other landholders, and private companies, is positively related to adoption, through enhanced trust in the advice of the advocates (e.g. Anderson 1981; Marshall 2004a, 2005).

(v) Ethnic and cultural divisions within a landholder population can act as significant barriers to the flow of information about environmental innovations (Stoyles 1992).

(vi) Extension, promotion and marketing programs by government workers and/or the private sector can be positively related to adoption (e.g. Llewellyn 2002; Marsh et al. 2000). Characteristics of extension agents that enhance effectiveness of extension are discussed in the Implications section later.

Demographic and situational variables are judged to be important because they will influence the goals of the landholder and potentially influence the capacity to adopt an innovation. Some examples of these variables are listed below.

(i) Cary et al. (2001) found that profit expectations are an important influence on investment plans (and, thus, on adoption decisions). Lack of financial viability would be expected to inhibit adoption of innovations by reducing the capacity to adopt, rather than the benefits of adopting. Cancian (1979) conducted a meta-analysis of the relationship between income and adoption and concluded that it may not be linear.

(ii) Access to and reliance on off-property income can influence the adoption of practices by increasing financial security but also by decreasing the tendency to adopt some practices that would increase 
profitability but involve greater management demands (Kebede 1992).

(iii) Property size is often, but not always, related to innovation adoption (e.g. Abadi Ghadim et al. 2005) - larger areas tend to increase the overall benefits of adoption of beneficial innovations and so increase the likelihood of adoption. Alternatively, social issues related to adoption may also lead to adopters having larger properties. In northeast Victoria, conservation cropping technology was more likely to be owned by operators of larger and specialist cropping enterprises rather than owners of smaller or opportunistic cropping enterprises (Wilkinson and Cary 1993). In north-central Victoria, the adoption of perennial pastures was strongly related to property size, but the adoption of tree planting was not (Wilkinson and Cary 1992). D'Emden et al. (2006) also found a lack of relationship between farm size and adoption of conservation tillage in Western Australia.

(iv) Age would appear to be of particular relevance to adoption of conservation practices that have long lags between investment and payoff. If a farm is not to be passed on to the farmer's children, and if the benefits of conservation practices are not expected to be fully reflected in the sale price of the farm, then older farmers may have less incentive to invest in something that will be primarily of benefit to the subsequent owner (Gasson and Errington 1993). We speculate that age may also influence adoption via a correlation with physical health. However, the evidence of a relationship between adoption and age, stage of life or experience is mixed. The most extensive metareview of socio-economic factors influencing adoption found both positive and negative relationships between age and adoption (Rogers 2003). The limited research addressing the influence of age on adoption of conservation practices (e.g. Cary et al. 2002; Curtis and Byron 2002; Latta 2002) is just as mixed.

(v) There can sometimes be relationships between education and the adoption of conservation practices. It has often been concluded that beneficial innovations tend to be adopted more quickly by landholders with higher levels of education (e.g. Feder et al. 1985; Goodwin and Schroeder 1994; Kilpatrick 2000; Rahm and Huffman 1984). However, in the case of a complex technology or practice that is actually disadvantageous when all of its effects are considered, education may tend to reduce or delay adoption by allowing the limitations of the practice to be recognised (e.g. Marsh et al. 2006). These limitations may go unrecognised by less educated landholders, who consequently adopt the practice mistakenly. Kilpatrick (2000) has shown the catalysing impact of education in general (not just agricultural education and training) on farmers' abilities and levels of 
interest in modifying farming practices. Given the decline in the traditional family farm apprenticeship as a means of entering farming in preference for a longer period of education (Barr 2004), the future farm management force will be increasingly educated and, presumably, increasingly interested in on-going self education about farming systems. Nevertheless, we suggest that a farmer's general level of education is likely to be less important as a predictor of adoption than their participation in specific relevant training courses.

(vi) The reason for holding land (e.g. agricultural production vis a vis lifestyle) can influence adoption decisions. As Vanclay (2004, p. 214) observed, 'Different farmers have different priorities, different understandings, different values, different ways of working, and different problems'. Regions within comfortable driving distance of major cities and regional centres in some Australian states (particularly New South Wales and Victoria) have seen social and demographic changes resulting from city dwellers purchasing what was formerly extensive farming land and pursuing their rural dreams. In these regions, traditional commercial agriculture has become a less important land use than it once was, occupying a declining proportion of the land, and the trend in this direction will continue (Barr and Wilkinson 2005). The new landholders may not have the time or financial resources for investment in large-scale adoption of expensive conservation practices (e.g. establishment of woody perennials) even if such practices would be financially beneficial in the long run (Nicoll 1994). Vanclay et al. (1998) promoted the idea of 'farming styles' as a useful mental model for making some sense of this diversity of farming objectives. The farming styles approach has been used in an exploratory fashion to try to explain conservation innovation adoption with mixed success (Howden et al. 1998; Howden and Vanclay 2000; Mesiti and Vanclay 2006; Vanclay et al. 2006).

\subsection{ATTRIBUTES OF PRACTICES THAT AFFECT ADOPTION INNOVATIONS}

We consider that there are two broad categories of characteristics of a technology or practice that drive its adoption or non-adoption: its relative advantage and its trialability. Relative advantage refers to the perceived net benefits if you do adopt, while trialability refers to how easy it is to move from non-adoption to adoption via a learning phase. Other characteristics that are mentioned in the literature will be discussed under these broad headings. 


\section{Relative advantage}

Relative advantage means 'the degree to which an innovation is perceived as being better than the idea [or practice] it supersedes' (Rogers 2003, p. 229). Relative advantage depends on the landholder's unique set of goals and the biophysical, economic and social context where the innovation will be used. Relative advantage is the decisive factor determining the ultimate level of adoption of most innovations in the long run.

Relative advantage depends on a range of economic, social and environmental factors, such as:

(i) The short-term input costs, yields and output prices of the innovation or of other activities that it affects. For example, Marsh et al. (2000) and Abadi Ghadim et al. (2005) found that the short-term profitability of new legume crops (e.g. lupins and chick peas) significantly influenced their adoption. Sinden and King (1990) and Cary and Wilkinson (1997) found that short-term expectations about variables related to profitability influenced the adoption of conservation practices.

(ii) The innovation's impact on profits in the medium-to-long term. The relative importance of short-term and long-term profits depends on the individual's personal goals and circumstances, but most farmers profess concern with outcomes beyond the short-term (Makeham and Malcolm 1993; Wilkinson and Cary 1992).

(iii) The innovation's impacts on other parts of the system within which it will be embedded. For example, a legume crop or pasture can increase the yield of subsequent cereal crops by nitrogen fixation and impacts on crop disease (e.g. Pannell 1996). Long-lived trees may reduce the flexibility of crop producers who wish to switch in and out of crop production from year to year in response to weather conditions - an important strategy in some low-rainfall environments (Cary 1986; Kingwell et al. 1993).

(iv) Adjustment costs involved in adoption of the innovation. One reason that the adoption of integrated pest management has been relatively slow is the relatively high adjustment cost it entails (Wiebers 1992). Of course, adjustment costs can be borne if the attraction of a practice is strong enough, as has widely occurred with conservation tillage.

(v) The innovation's impacts on the riskiness of production (Abadi Ghadim et al. 2005; Marra et al. 2003). The relative advantage of an innovative land use would be reduced if it were perceived to be more subject to price variability, to establishment failure, or to yield losses due to drought, weeds or pests than the current land use.

(vi) The innovation's compatibility with a landholder's existing set of technologies, practices and resources (Kaine and Lees 1994). For 
example, a new higher yielding wheat variety is readily adoptable by an existing wheat farmer because it is compatible with the farmer's current machinery, rotations, agronomic practices, herbicide usage, and so on. However, to such a farmer, a new type of tree crop is unlikely to be as compatible with existing practices, so the cost of making the transition to a new farming system that includes the tree crop would tend to reduce its relative advantage and moderate its adoption. Some practices are sensitive to the soil types on which they are used, and so may have higher relative advantage on some farms with particular soils. For example, different crops prefer sandy soils or loamy soils. Some plants are sensitive to soil acidity or soil salinity and some are tolerant, influencing their attractiveness to a farmer depending on which soils are present on the farm. One resource that is a critical determinant of a farmer's ability to make an innovation work is their own management skill.

(vii) The innovation's complexity (Rogers 2003; Wilkinson 1989). Complexity may increase the intensity of effort required for ongoing management, and the risk of the innovation failing in any given year, each of which reduces the innovation's relative advantage. Alternatively, an innovation may be no more complex in itself, but adoption of it may add to the overall complexity faced by the land manager. For example, a farmer considering a suite of crop types may find that the managerial complexity of managing five different crops on the farm, each with its own requirements for machinery, agronomy, marketing, and storage, is unacceptably greater than the complexity of managing four. Even if the fifth crop type would actually be profitable to adopt, this could be outweighed by considerations of inconvenience, stress and risk. Likewise, the conversion from an annual pasture production system to one including perennial pastures such as lucerne can entail significant flow-on impacts upon the farm system.

(viii) Government policies. Relative advantage can be affected positively or negatively by government policies. For example, in the US, support programs that are based on yield tended to increase the relative advantage of the intensification of farming and thus increase adoption and use of herbicides (Helms et al. 1987; Miranowski et al. 1991).

(ix) The cost or profitability of the traditional practice which the innovation would replace. For example, increases in the price of fuel and labour tended to increase the adoption of herbicides in the US, as herbicides substituted for cultivation which was becoming more costly (Carlson and Wetzstein 1993; Miranowski and Carlson 1993). As another example, D'Emden et al. (2006) found that the adoption of conservation tillage in Australia has been significantly affected by 
the ratio of glyphosate to diesel prices. They estimated that the time to adoption was halved because of the fall in the relative price of glyphosate over the study period. Further, a history of specialisation in a particular practice is likely to increase the farmer's skill level and managerial abilities specific to that practice, and so reduce the financial relative advantage of an alternative innovation.

(x) The compatibility of a practice with existing beliefs and values. At least in the short-to-medium term, farmers may consider themselves to be wedded to production of a particular output (e.g. grain cropping, not livestock or trees) or to a particular method of production (e.g. traditional farming methods, not organic) because they identify with it personally (e.g. all my friends are wheat farmers, I am a wheat farmer too, it is what I like doing, it is what I'm good at, it is what my family does, it is an important and respectable occupation for me). This reduces the relative advantage of alternatives.

(xi) The impact of the innovation upon the family lifestyle. The failure of marital relationships is one of the major causes of farm business failure (Barr 1999). To most farming families, the farm is the means towards the goal of a secure family life. Some innovations can cause a change in the quality of the family lifestyle or potentially even marriage relationships, and so their relative advantage can be strongly affected by this. In the eastern wheatbelt of Western Australia, the large-scale introduction of perennial pastures into a cropping system may threaten the traditional summer holiday that allows the family to temporarily escape the harsh summer wheatbelt environment. The adoption of redesign of the farm irrigation system in northern Victoria was in part assisted by the advantages of less broken sleep and more time for couples to share in the evening.

(xii) Self-image and brand loyalty. Relative advantage can be affected if an innovation changes the social standing of people within the local culture. In some situations this can accelerate the rate of adoption while in others it can retard adoption. The adoption of cross-breeding of beef cattle was slowed in the high-rainfall beef zone by the traditional status gained by the production of pure-bred Hereford cattle. Although minimum-tillage techniques are now widely adopted, early adopters tell stories of the social challenges of not cultivating while neighbours were busy cultivating and maintaining a social network through tractor-cabin CB radios. The social stigma of having an 'untidy' farm (one without straight furrows) also delayed the adoption of zero-till (Coughenour and Chamala 2000).

(xiii) The perceived environmental credibility of the practice. We would expect environmental credibility to enhance the relative advantage of a practice. Environmental advantage is not always clearly observable, 
as recent changes in the understanding of dryland salinity attest (Ridley and Pannell 2005). In north-central Victoria, trees and perennial pasture have differed in their environmental credibility for dryland salinity management. Tree planting by farmers was based on 'symbolic' beliefs (symbolising a personal expression of concern for the public good), while pasture sowing was based on 'instrumental' beliefs (providing tangible personal benefits such as increased production) (Cary 1993). Consequently, farmers planted a similar number of trees no matter what size their farm, while those with large farms tended to sow a larger area of perennial pasture than those with small farms (Wilkinson and Cary 1992).

The crucial role of 'relative advantage' as a driver of adoption, and the importance of profit as one of the drivers for most farmers, has strong implications for conservation practices. Among those farmers with a focus on profit, the farm-level economics of a proposed conservation practice will be important. Those conservation practices that are not profitable at the farm level will tend to be adopted only by farmers with stronger conservation goals. The lower the perceived profitability, the stronger the conservation goals need to be for adoption to occur. Unprofitable conservation practices are likely to be more widely adopted if they are able to generate conservation benefits when adopted at a small scale. Conservation land uses that require adoption at large scale to generate conservation benefits will probably not be adopted sufficiently if they are perceived to be less profitable than the land uses they replace.

There are numerous examples that illustrate and reinforce these implications. There has been a very widespread but small-scale adoption of unprofitable conservation practices among many landholders, triggered in part by government programs such as the National Landcare Program and the Natural Heritage Trust (Mues et al. 1998). For example, the resources committed to fencing off streams and remnant vegetation attest to the conservation concerns of many landholders. However, for all but a minority of farmers, the costs and areas involved are small relative to the scale of the farm businesses (e.g. Curtis and De Lacy 1996).

Some conservation-related practices have been adopted very widely and over very large areas in Australia, most notably reduced tillage and liming of acid soils (e.g. Mues et al. 1998). These are both practices that contribute positively to farmers' economic goals in the medium term in many locations. This highlights that the relative advantage that drives adoption may not necessarily relate to the environment. Indeed, environmental benefits can often be most readily achieved by developing conservation practices that provide a commercial advantage to farmers.

Conversely, the scale of adoption of perennials for salinity abatement in low- to medium-rainfall areas has been much less than needed to 
significantly reduce the salinity threat (e.g. ABS 2002; Kington and Pannell 2003). A recent comprehensive review of the economics of salinity abatement measures available to grain growers provides a convincing explanation for this, as there were few examples of locations and practices where the economics favoured high levels of adoption (Kingwell et al. 2003).

Other factors that tend to reduce the relative advantage of at least some conservation practices are as follows.

(i) High establishment costs. Land conservation practices are often characterised by high up-front costs, and benefits that occur some time in the future (e.g. the establishment of woody perennials for salinity mitigation). Large up-front costs plus accumulated interest therefore reduce the attractiveness of these practices.

(ii) Long time scales. A number of the land degradation issues of concern are long-term by nature. In some cases, degradation processes of concern occur over decades (e.g. dryland salinity, soil acidification, decline of remnant native vegetation) and the practices designed to ameliorate the degradation can be slow to take effect. For this reason, land conservation innovations are often particularly susceptible to the problems of up-front costs and delayed benefits, as outlined above. It also means that those landholders who are forced by circumstances to give priority to short-term profits are unable to adopt even if the innovation would eventually generate benefits sufficient to offset the up-front costs plus interest.

(iii) Riskiness. Long time lags between planting and harvest (e.g. decades for many woody perennials) contribute to the riskiness of production, because it gives scope for unanticipated developments in product markets, development of competing technologies, accidents or natural events (e.g. fire or pests) to damage the harvestable product.

(iv) Complexity. Some conservation practices are relatively complex, further reducing their relative advantage. For example, many farmers perceive that lucerne pasture (a perennial pasture plant that helps in salinity management) requires a greater intensity of management than do traditional annual pastures (e.g. Lodge 1991). The prospect of expanding the portfolio of farming activities by adopting additional land uses for conservation purposes is likely to be perceived as increasing the overall complexity of the land management system. Greater complexity may contribute to an increased risk of failure.

(v) Spillovers. Some of the benefits from conservation practices can extend to individuals other than the adopting landholders. A result can be that adoption is less than it would be if the landholder considered all the benefits to the broader community. However, there is scope in some cases for landholders to reciprocate part or all of the benefits 
they obtain from one another's adoption, and, thus, narrow the gap between the interests of potential adopters and the wider community. An example is shallow groundwater pumping to lower the watertable beneath adjoining irrigation properties. In such a situation, adoption of pumping on any of the properties would lower the watertable not only on that property but, to a lesser extent, on the neighbouring properties as well. If a landholder expects the neighbouring landholders to reciprocate his or her investment in pumps, the incentive for the first landholder to invest is increased. However, the expected relative advantage to any landholder from adopting will be lower if the reciprocation cannot be trusted (i.e. if the other landholders are expected to 'free ride' on the actions of the first landholder) (Marshall 2004b, 2005).

Given that it can be difficult for landholders to develop mutual trust, a perception that adoption of a conservation practice generates reciprocal spillover benefits can itself be a disincentive to adoption, even if the perception is incorrect. As an example where this occurred, in the 1980s and '90s, there developed a widespread misperception among Australian farmers that adoption of measures to ameliorate dryland salinity on farms generates reciprocal spillover benefits, although this is rarely true in reality. For many farms (particularly in Western Australia), the control of salinity is solely dependent on actions within the farm boundary (Pannell et al. 2001). In all states where spillovers from dryland salinity are significant, they are almost always unidirectional (uplands affecting lowlands) rather than reciprocal.

\section{Trialability}

In the previous section we discussed a number of social, cultural and personal factors that influence learning about an innovation. Here we consider characteristics of the innovation itself that affect how easily the landholder can learn about its performance and optimal management - in other words, the trialability of the innovation. Trialibility does not merely refer to the ease of physically establishing a trial, but encompasses factors that influence the ability to learn from a trial, such as the complexity of the issue being addressed.

Trialability has been found to enhance adoption (e.g. Ohlmer et al. 1998). As noted earlier, trialing an innovation provides information that reduces uncertainty about the relative advantage of the practice (Tonks 1983). Thus, trialing is important because it can increase the probability of the landholder making a correct decision. Trialing also provides an opportunity for the landholder to learn the skills needed to apply the innovation. The small-scale nature of a trial allows the landholder to avoid the risk of large financial 
costs if the practice turns out to be uneconomic or fails due to inexperience. The reductions in uncertainty and risk from these two aspects are themselves of benefit to the majority of people who are psychologically averse to risk and uncertainty.

The trialability of a practice is affected by a number of factors, including those listed below. Note that several of these factors were also listed as influences on relative advantage. These factors influence adoption through both channels.

(i) The divisibility of an innovation refers to its use on a small scale, or the use of a subcomponent of an innovation package. A degree of divisibility is essential to allow small-scale trialing for learning purposes (Leathers and Smale 1992). For example, a new herbicide would be trialable on a very small scale. In contrast, a new land use intended to contain a rising watertable requires a minimum scale for its effects to be apparent and hydrological evidence indicates that the necessary scale for impacts to be apparent at any distance from the trial is very large (e.g. George et al. 1999). Indeed, it appears that almost full adoption is often necessary. High fixed costs for an innovation (e.g. the need to purchase new machinery) reduce its divisibility. Even when an innovation package is promoted to farmers as a tightly-bundled, complex technology, farmers have a strong propensity to pull it apart and adopt only some of its components, or adopt selected components in a stepwise manner (Wilkinson 1989).

(ii) The observability of results from an innovation is positively related to adoption (Pannell 2001b), at least in part, due to its influence on trialability. Trialing a practice becomes less costly, and thus more likely to be seen as worthwhile, the greater the observability of trial outcomes. Higher observability means that fewer trials may be necessary to sufficiently reduce uncertainty to make the choice between adoption and non-adoption. Observability also enhances the prospects of 'over the fence' learning by landholders, and, thus, promotes diffusion of a practice (Geroski 2000; Shampine 1998). The impacts of a new production-oriented practice (e.g. a new herbicide) are often readily and rapidly observable. In contrast, a new land use intended to control a rising watertable in a neighbouring paddock may have effects that are long delayed and physically difficult to observe, requiring the costly installation of piezometers. Even when a piezometer reading is obtained, given the considerable complexity and heterogeneity of underground geological structures in agricultural regions of Australia, it can be difficult to know how representative the observation is. Perhaps in recognition of the importance of observability, there have been a number of initiatives attempting to 
increase the observability of watertable rise (e.g. Watertable Watch bore flags in Victorian irrigation settlements in the 1980s).

There is also considerable difficulty in attributing any change in a watertable to the practice that is being trialed. One difficulty is the absence of a suitable control against which the result can be compared. When trialing an innovation, such as a new grain crop variety, it is relatively easy to compare the crop's performance with traditional varieties in the same growing conditions. When trialing an agronomic practice, results can easily be compared with and without the practice. However, for a perennial plant enterprise established in order to prevent rises in the watertable, such comparisons are much more difficult and less informative.

It may be that the only available method for assessing the impact of an area of perennials on the watertable would be to observe the deviation from a previously recorded trend. The need to look for a deviation in a historic trend, rather than comparing two current treatments, would add to the delay before any conclusion could be reached with confidence. This is because, in the absence of a control treatment, it is more difficult to determine whether any observed deviation is attributable to the new practice or to other factors, such as atypical rainfall. Uncertainty about the response lag time adds to the difficulty of interpreting any observed trend deviation.

(iii) The longer the lag, the less trialable is the innovation. For example, even if observability was high, and a control treatment was available for comparison, groundwater movements are slow, so it may be a long time before a landholder's uncertainty about the soundness of a practice for groundwater management is sufficiently reduced to prompt widespread adoption. Slowness reduces the overall value of trialing and may contribute to a judgment that the benefits of the trial do not outweigh the costs.

(iv) The complexity of an innovation is negatively related to its trialability and eventual adoption. The greater the complexity, the greater the information that landholders require to be certain about the consequences of adopting it. In a sense, this aspect of complexity is related to the innovation's observability. If there could be multiple consequences from adoption, it is more difficult or expensive to observe them all, and landholders may take a longer duration of trialing to develop confidence in their judgments. A separate issue is that greater complexity of an innovation will likely increase the risk of technical failure when conducting the trial. In general, greater complexity increases the difficulty, required effort and time to learn about the innovation's performance and how best to implement it. 
This reduces the anticipated value of trialing and so may discourage it from occurring, to some extent.

(v) The cost of undertaking a trial will be negatively related to adoption. For example, if seed of a new crop is in short supply, and so temporarily expensive, farmers may decide to delay their trialing of the crop. Where a large-scale trial is necessary (e.g. for water management technologies), the cost of trialing is correspondingly larger, and trialing is therefore less attractive. A large trial consumes land, labour and finance which could otherwise be used productively. In these ways, high costs reduce trialability.

(vi) Threats to a biological trial may include drought, diseases, pests, and establishment failure. Trials of any innovation always face a risk of failure, but given the large area for which a trial of a tree enterprise appears necessary to discern watertable impacts, the potential losses from a trial failure are relatively large. This provides further discouragement to a risk-averse landholder considering such a trial.

(vii) For the information from a trial to have value for decision making, the trial needs to be indicative of the innovation's performance in the long run. If the technology or practice used in the trial is implemented poorly, then the trial will clearly be less likely to meet this requirement. Poor implementation is more likely when the innovation is radically different from practices with which the landholder is familiar, and this does appear to describe the situation for some conservation practices.

(viii) Similarity in behaviour of the innovation to a familiar practice can be helpful in the learning process, and so, in a sense, can enhance trialability. For example, if the pattern of yield responses to weather for a new crop is similar to that for familiar crops, a farmer can extrapolate more readily from a small number of observations of the new crop. Abadi Ghadim et al. (2005) found that differences among farmers in their perceptions about the similarity of responses between yields of a new crop (chick peas) and a traditional crop (wheat) was a significant variable explaining their adoption intentions. New conservation-related land uses are likely to be less similar to traditional land uses in their behaviour than are new productionoriented technologies.

(ix) The presence of spillover effects can reduce the motivation for trialing. In a survey of farmers in the upper Kent River catchment of Western Australia, Kington and Pannell (2003) found that 62 percent of farmers believed that their neighbours were causing spillover salinity impacts. Although the survey did not explore the proportion of the problem that was attributed to inter-farm flows, it appeared that many of these farmers were significantly over-rating the extent of the 
spillover problem (Pannell et al. 2001). If farmers believe (rightly or wrongly) that the rise in their watertable is due to the management practices of their neighbours, their motivation to trial a practice for groundwater control on their own farm is reduced.

\subsection{IMPLICATIONS}

\section{Implications for research}

Following Marsh (1998), we provide the following suggestions for biophysical scientists to help them achieve greater adoption by landholders of conservation practices being researched.

(i) Be conscious of the type of practices that landholders adopt more readily - those with high relative advantage and high trialability. Appreciate that landholders have legitimate reasons for non-adoption (Vanclay 2004). If the community has a wish to reduce a particular form of environmental degradation originating from rural properties, but the available practices for reducing the degradation conflict with goals of landholders (e.g. salinity treatments highly unprofitable to farmers), one sound response for scientists is to consider the viability of developing new technologies or practices that achieve both community and landholder goals.

(ii) Encourage a participatory process. Working with landholders forces researchers (and extension workers) to recognise that their own goals may be different to landholders' goals, and reduces the risk of them making incorrect or over-simplified assumptions about what landholders' goals really are. In a participatory project, the research/extension can be adapted in response to this improved understanding. Such interaction also increases landholders' knowledge of the research and their ownership of, and faith in, the results. It may help landholders to understand and appreciate the goals of researchers. Participation also helps to develop better programs and recommendations by making better use of local knowledge so that recommendations are more often corroborated by subsequent experience, and in this way promotes landholders' trust in research, development and extension over the longer term.

(iii) Look constructively at what landholders are doing already. Work with them where possible rather than against them (or at least acknowledge the difficulty of getting them to stop believing that what they are already doing is appropriate). This suggestion acknowledges the importance of local knowledge in landholders' decision making, and 
the importance of respecting their personal goals and perceptions. We suggest that scientific and local knowledge can be highly complementary.

(iv) As we have argued, adoption of conservation practices by landholders is not solely a biophysical issue, it is also an economic, social and psychological issue, so biophysical researchers can benefit from working closely with economists, sociologists and psychologists. Social scientists should be involved in projects from an early stage, including in problem definition and project design, so that their advice can influence the direction of the research, rather than being limited to analysing the results (e.g. attempting to explain landholders' responses or lack of response).

Attending to these suggestions would help to enhance trust and credibility in the relationship between researchers and landholders. This is crucial if researchers are to influence the adoption process.

Kaine and Lees (1994) suggested the idea of research and development market segmentation on the basis of farming contexts, and Kaine et al. (2005) proposed the same idea for extension. Mesiti and Vanclay (2006) used a farming styles approach as an alternative to market segmentation. Market segmentation may be less straightforward in agricultural research and extension than in retailing, where variables like age, education and income have proven useful. The most useful variables in differentiating market segments among landholders are often psychological rather than demographic, and hence are more difficult to observe. Nevertheless, in practice, agricultural and environmental research and development does focus on locally relevant issues to a considerable extent. Kaine and his coauthors use an approach where the focus is on the farm context itself and the fit of the innovation within that context.

Given the importance of trialability for adoption of an innovation, it may be useful for researchers and extension agents to consider ways in which landholder learning from trials can be enhanced. One possibility suggested by Abadi Ghadim et al. (2005) is to provide information about the trial performance of familiar reference land uses or practices that are as similar to the innovation as possible, in conjunction with information about the performance of the innovation. It may be feasible to facilitate physical observation, or at least present results of physical measurements, of important processes that are not readily visible (e.g. groundwater processes). Perhaps it is possible to provide rules of thumb about final yields based on the early growth rates of plants that have long lags before harvest (e.g. woody perennials). Similarly, where a novel land use requires large-scale adoption to achieve environmental benefits, ways to predict those benefits based on performance in small-scale trials may be helpful. 


\section{Implications for extension}

A criticism of traditional extension is that it viewed the extension process primarily as a matter of communication. Lack of adoption was blamed on a failure of the extension communication process. The solution was to better target extension and to improve the methods of information delivery. The assumption was that farmers were information deprived and relatively passive recipients of knowledge. In reality, farmers have excessive information (e.g. from consultants, banks, accountants, agronomists, agribusiness firms, other landholders), some of which is conflicting, and they are almost never passive recipients. Recognising its place within this complex web of information sources, extension needs to be more focused on credibility, reliability, legitimacy, and the decision-making process. Features of current conservation-related extension that mitigate against the development of credibility include: short-term funding, rapid turnover of staff, the youthfulness and inexperience of many staff, and the lack of technical farming expertise of many staff (Vanclay and Lawrence 1995).

\section{Expectations for extension}

Even with the most expert and persuasive extension, landholders are not likely to change their management unless they can be convinced that the proposed changes are consistent with their goals. Therefore, expectations about the extent of change that is likely to result from extension need to be realistic (Vanclay 2004). Large changes made by large numbers of landholders are not likely to be attributable to extension in most cases, partly because landholders and their lands are highly heterogeneous. Any given practice only advances the goals of some landholders, and often only on some of their land.

It is likely that the main contributions of extension will be through raising awareness and, to some extent, changing perceptions of the relevance and performance of an innovation. It is much more difficult (and sometimes ethically contentious) to change people's goals. It seems that the Landcare movement in Australia has increased the emphasis given to conservation goals by landholders, but the extent of increase has been modest for most landholders (Reeve 2001) and the movement has, perhaps, reached the limits of its influence (Reeve et al. 2002).

This suggests that for many innovations, extension's main role will be to accelerate the adoption process, rather than to lift the final level of adoption (Marsh et al. 2000). Exceptions to this may include practices which would have entirely failed to diffuse in the absence of extension, perhaps due to problems with trialability (e.g. low observability, high complexity). Related 
to this, extension is unlikely to persuade landholders to make greater use of a practice with which they already have personal experience, unless the extension provides new information about a change that increases the attractiveness of the innovation (e.g. new information about how to better implement the innovation, or about new incentive payments to encourage adoption).

Another important issue for extension (as for science) is that it does not have automatic legitimacy and credibility (Vanclay 2004) - these have to be earned. A landmark study of the social process of agricultural extension in the 1970s showed that the key determinant of an adviser's credibility to a farmer was trust. Trust was, in turn, strongly related to the extent a farmer believed an adviser understood and respected the goals of the farmer (Anderson 1979, 1981). Trust determines the nature of the role that an adviser may play in the social aspects of the decision-making process of the landholder. Without trust, an adviser may only expect to participate as a provider of information that will be later evaluated within a closer circle of trusted contacts (Phillips 1985). The adviser who is trusted may be invited to participate at a deeper level of decision making where information is more deeply assessed against the goals of the landholder. Participation at this level of decision making is important in gaining understanding of the process of adoption and adaptation that determines the fate of conservation practices. The next section includes suggestions of how credibility and trust may be achieved.

\section{The conduct of extension}

Here we briefly present some suggestions about the conduct of extension that can be related to the findings we have reported earlier. It is not an exhaustive manual of extension methods, but focuses on core issues related to enhancing adoption.

Any sound extension campaign needs to use multiple methods (Vanclay 2004). Multiple extension channels, repetition, multiple deliverers of the message, and harnessing of peer pressure are among the standard tools of effective extension agents. Reliance on any particular method (e.g. print articles, verbal presentations, group extension, advertisements) will fall short of the potential impact on adoption from a diverse portfolio of extension approaches and channels. One advantage of using multiple approaches is that it increases the chances of reaching more of the relevant groups of landholders. Additionally, different landholders have different learning styles and prefer to receive information in different ways, or through different channels (Bardsley 1982). Also, repetition can help to reinforce a message 
and build confidence, especially if it comes through different channels and from different sources.

Llewellyn et al. (2005) argued for a more sophisticated approach to selecting which landholder perceptions to target with extension. Through their research on farmer adoption of Integrated Weed Management practices, they found that, of the many variables about which farmers held perceptions, only a small minority could be usefully targeted by extension. The majority of variables were either perceived accurately already (in which case there was nothing for extension to do) or would not be influential on adoption behaviour (in which case extension would not be useful). These insights appear to provide a useful pathway for improving the cost-effectiveness of extension.

In situations where adoption of innovations by a group of landholders confers reciprocal spillover benefits, developments in the theory of collective action (Ostrom 1998) suggest that adoption of these innovations may be enhanced by promoting the learning of social norms that emphasise mutual benefit/reciprocal benefits, and by efforts to build the mutual trust within that group (Marshall 2004b, 2005).

A notable trend in extension practice in Australia over the last 15 years has been the substantial decline in public funding for traditional one-on-one extension and a rise in group-based extension (Marsh and Pannell 2000). It could be argued that group-based extension has never been funded at a level that would allow its efficacy to be comprehensively tested (Curtis 2000). Nevertheless the data of Mullen et al. (2000) show that increased funding for what could broadly be called group-based environmental extension (including group facilitators) has roughly offset the decline in traditional production-oriented extension. Group-based extension is, of course, an important part of the extension system, but like any extension approach it has its limitations (Vanclay 2004). In the 1990s, group-based extension processes came to be relied on in the National Landcare Program, partly in response to perceptions about their ability to harness peer pressure to address what were often perceived (incorrectly in some cases) to be environmental problems requiring collective action by landholders for their effective resolution. Group-extension processes grew in favour among extension theorists in response to an increased emphasis on adult learning principles and participation by stakeholders (Chamala and Keith 1995; Knowles 1984; Röling 1988). They were embraced by state agriculture agencies, in significant part, for budgetary reasons (Barr 1994; Marsh and Pannell 2000).

Although group-extension approaches are undoubtedly useful, the swing from individuals to groups may have gone too far. For example, the introverted personality profiles of graziers described in the work by Shrapnel and Davie (2001) indicate the continued importance of one-on-one extension. Noting the importance of credibility in effective extension, 
Vanclay (2004, p. 221) observed that, 'Credibility is developed over time through the provision of credible, practical, useful answers that assist farmers in [their] day-today operations. Group facilitators who never provide on-farm advice rarely develop credibility and their ideas are easily dismissed'.

We have previously discussed the importance of credibility, trust and confidence in extension agents on the part of a landholder. A history of valuable advice relevant to a landholder's goals is probably the single most important source of credibility, but it can be enhanced to some extent by a wide range of factors, including: (i) authority and technical expertise of the extension agent; (ii) perceived similarity of the extension agent to their audience; (iii) local profile of the extension agent (e.g. local residence); (iv) communication skills of the extension agent; (v) personal relationships between the extension agent and landholders; and (vi) extension-agent acknowledgment of/empathy with the circumstances and problems of landholders.

Adviser credibility and trust is a valuable commodity, but it is only earned slowly. Adviser credibility and trust can be easily lost by the support of an innovation or practice clearly unsuited to local circumstances, or through the evangelical promotion of a practice that is clearly in conflict with the goals of landowners. In the past 20 years, the role of government extension agents in many states has changed away from that of supporting landholders in making good decisions to achieve their own goals, towards encouraging landholders to make decisions that achieve outcomes for the public good. In many situations, this has the potential to reshape the social contract between adviser and landholder, creating a far more complex social interaction that may be less comfortable for both. The importance of this changed social relationship is not recognised by the relevant public agencies, which publicise their programs using the rhetoric of community development, yet place clear requirements for technology transfer outcomes upon their agents.

\section{Implications for policy and for regional bodies}

As noted in the introduction, some government officers express frustration at the lack of adoption by landholders of conservation practices and call for additional social research to better understand adoption. Sometimes it can be helpful to better understand the adoption of specific practices, but the influences on adoption in general have been studied intensely and we believe that they are sufficiently well understood. Rather than more research into adoption, the more pressing need is to apply what is already well established in the adoption literature.

As we have seen, one implication is that if a practice is not adopted in the long term, it is because landholders are not convinced that it advances their 
goals sufficiently to outweigh its costs. A consequence of this is that we should avoid putting the main burden for promoting adoption onto communication, education and persuasion activities. This strategy is unfortunately common, but is destined to fail if the innovations being promoted are not sufficiently attractive to the target audience. The innovations need to be 'adoptable'. If they are not, then communication and education activities will simply confirm a landholder's decision not to adopt, as well as degrade the social standing of the field agents of the organisation. Extension providers should invest time and resources in attempting to ascertain whether an innovation is adoptable before proceeding with extension to promote its uptake.

For some environmental issues, the real challenge is to find or develop innovations that are not only good for the environment, but also economically superior to the practices they are supposed to replace. If such innovations cannot be identified or developed, there is no point in falling back onto communication. Promoting inferior practices will only lead to frustration for all parties.

Sometimes unattractive practices can be made sufficiently attractive by the provision of financial incentive payments (e.g. through economic policy instruments). However, it is important to be realistic about the potential of this approach. In some cases, the level of payment required to achieve sufficient adoption would be more than can be justified by the resulting environmental benefits (e.g. Pannell 2001a). In some situations, the most sensible strategy is not to attempt to encourage uptake of existing technologies or systems. Rather, it may be more sensible to attempt to develop better practices (more effective or more adoptable), or it may be that research and policy needs to address the task of living with the problem.

In conclusion, we set out to provide an integrated review of several disciplinary literatures on the adoption of conservation practices by rural landholders. We found that many of the findings and perspectives of our separate disciplines are consistent and readily translatable across disciplinary boundaries. We discussed these findings in three broad groupings: those relating to adoption as a process of learning, those relating to characteristics of potential adopters, and those relating to characteristics of the conservation practice. In general, adoption of conservation practices is complex and multifaceted, but it is, nevertheless, reasonably well studied and understood. In light of the literature, the disappointing levels of adoption of conservation practices that are often observed are readily explicable in terms of characteristics of the learning process, the potential adopters or the conservation practices. We have identified a number of important implications of the review for research, extension and policy. 


\section{ACKNOWLEDGMENTS}

The authors are grateful to anonymous reviewers and to Amabel Fulton and Sally Marsh for their detailed and insightful suggestions. Funders who have contributed directly or indirectly to the preparation of this review include Land and Water Australia, the Australian Research Council, Rural Industries Research and Development Corporation, Grains Research and Development Corporation, and the CRC for Plant-Based Management of Dryland Salinity.

\section{REFERENCES}

Abadi Ghadim, A.K. and Pannell, D.J. (1999). A conceptual framework of adoption of an agricultural innovation, Agricultural Economics 21, 145-154.

Abadi Ghadim, A.K. and Pannell, D.J. (2003). Risk attitudes and risk perceptions of crop producers in Western Australia, in B.A. Babcock, R.W. Fraser and Lekakis, J.N. (eds), Risk management and the environment: agriculture in perspective, Dordrecht: Kluwer, pp. 113-133.

Abadi Ghadim, A.K., Pannell, D.J. and Burton, M.P. (2005). Risk, uncertainty and learning in adoption of a crop innovation, Agricultural Economics 33, 1-9.

Anderson, A.M. (1979). How advisors advise: agricultural extension as a social process, Richmond: Hawkesbury Agricultural College.

Anderson, A.M. (1981). Farmers' expectations and use of agricultural extension services, Richmond: Hawkesbury Agricultural College.

Australian Bureau of Agricultural and Resource Economics (2003). Australian farm surveys report 2002, Canberra: ABARE.

Australian Bureau of Statistics (2002). Salinity on Australian farms, Report 4615.0, Canberra: Australian Bureau of Statistics.

Bardsley, B. (1982). Farmers' assessment of information and its sources, Melbourne: School of Agriculture and Forestry, University of Melbourne.

Bardsley, P. and Harris, M. (1987). An approach to the econometric estimation of attitudes to risk in agriculture, Australian Journal of Agricultural Economics 31, $112-126$.

Barr, N. (1994) Landcare from inside-out and outside in, Australian Farm Manager 5, 2-10.

Barr, N.F. (1999). Salinity control, water reform and structural adjustment: the Tragowel Plains irrigation district, $\mathrm{PhD}$ thesis, Melbourne: Institute of Land and Food, University of Melbourne.

Barr, N. (2004). The micro-dynamics of occupational and demographic change in Australian agriculture: 1976-2001, Canberra: Australian Bureau of Statistics.

Barr, N. and Cary, J. (2000). Influencing improved natural resource management on farms: a guide to factors influencing the adoption of sustainable natural resource management practices, Canberra: Bureau of Rural Sciences.

Barr, N. and Wilkinson, R. (2005). Social persistence of plant-based management of dryland salinity, Australian Journal of Experimental Agriculture 45, 1495-1501.

Black, A. (2000). Extension theory and practice: a review, Australian Journal of Experimental Agriculture 40, 493-502. 
Bond, G. and Wonder, B. (1980). Risk attitudes amongst Australian farmers, Australian Journal of Agricultural Economics 24, 16-34.

Cancian, F. (1979). The innovator's situation, Stanford: Stanford University Press.

Carlson, G.A. and Wetzstein, M.E. (1993). Firm decisions and behavior in pest management on a regional level, in Carlson, G.A., Zilberman, D. and Miranowski, J.A. (eds), Agricultural and environmental resource economics, Oxford: Oxford University Press, pp. 273-288.

Cary, J.W. (1986). Farmers' attitudes to land management for conservation, Melbourne: School of Agriculture and Forestry, University of Melbourne.

Cary, J.W. (1993). The nature of symbolic beliefs and environmental behaviour in a rural setting, Environment and Behavior 25, 555-576.

Cary, J.W. and Weston, R.E. (1978). Social stress in agriculture: the implications of rapid economic change, Melbourne: School of Agriculture and Forestry, University of Melbourne.

Cary, J.W. and Wilkinson, R.L. (1997). Perceived profitability and farmers' conservation behaviour, Journal of Agricultural Economics 48, 13-21.

Cary, J., Webb, T. and Barr, N. (2001). The adoption of sustainable practices: some new insights. An analysis of drivers and constraints for the adoption of sustainable practices derived from research, Canberra: Bureau of Rural Sciences.

Cary, J., Webb, T. and Barr, N. (2002). Understanding landholders' capacity to change to sustainable practices: insights about practice adoption and social capacity for change, Canberra: Bureau of Rural Sciences.

Chamala, S. and Keith, K. (eds) (1995). Participative approaches for landcare, Brisbane: Australian Academic Press.

Coughenour, C.M. and Chamala, S. (2000). Conservation tillage and cropping innovation: constructing the new culture of agriculture, Ames: Iowa State University Press.

Curtis, A.L. (1997). Landcare, stewardship and biodiversity conservation, in Klomp, N.I. and Lunt, I. (eds), Frontiers in ecology: building the links, Oxford: Elsevier Science, pp. 143-153.

Curtis, A. (2000). Landcare: approaching the limits of volunteer action, Australian Journal of Environmental Management 6, 26-34.

Curtis, A. and Byron, I. (2002). Understanding the social drivers of catchment management in the Wimmera, Albury: Charles Sturt University.

Curtis, A.L. and De Lacy, T. (1996). Landcare in Australia: does it make a difference?, Journal of Environmental Management 46, 119-147.

Curtis, A. and Robertson, A. (2003). Understanding landholder management of river frontages: the Goulburn Broken, Ecological Management and Restoration 4, 4554

Curtis, A., MacKay, J., Van Nouhuys, M., Lockwood, M., Byron, I. and Graham, M (2000). Exploring landholder willingness and capacity to manage dryland salinity: the Goulburn Broken catchment, Johnstone Centre report no. 138, Albury: Charles Sturt University.

D'Emden, F.H., Llewellyn, R.S. and Burton, M.P. (2006). Adoption of conservation tillage in Australian cropping regions: an application of duration analysis, Technological Forecasting and Social Change 73, 630-647. 
Dong, D. and Saha, A. (1998). He came, he saw (and) he waited: an empirical analysis of inertia in technology adoption, Applied Economics 7, 893-905.

Duncan, R.C. (1969). An investigation of the 'trial' stage in the adoption process: aerial topdressing in the Clarence Valley, Review of Marketing and Agricultural Economics 37, 207-216.

Feder, G. and Umali, D. (1993). The adoption of agricultural innovations: a review, Technological Forecasting and Social Change 43, 215-239.

Feder, G., Just, R. and Zilberman, D. (1985). Adoption of agricultural innovations in developing countries: a survey, Economic Development and Cultural Change 33 , 255-297.

Gasson, R, and Errington, A. (1993). The farm family business, Wallingford: CAB International.

George, R.J., Nulsen, R.A., Ferdowsian, R. and Raper, G.P. (1999). Interactions between trees and groundwaters in recharge and discharge areas - a survey of Western Australian sites, Agricultural Water Management 39, 91-113.

Geroski, P. (2000). Models of technology diffusion, Research Policy 29, 603-625.

Gibbs, M., Lindner, R. and Fischer, A.J. (1987). The discovery of innovations by farmers, Journal of the Australian Institute of Agricultural Science 53, 254-261.

Goodwin, B.K. and Schroeder, T.C. (1994). Human capital, producer education programs, and adoption of forward-pricing methods, American Journal of Agricultural Economics 76, 936-947.

Griliches, Z. (1957). Hybrid corn: an exploration in the economics of technological change, Econometrica 25, 501-523.

Griliches, Z. (1960). Hybrid corn and economics of innovation. Science 132, 275280.

Guerin, L.J. and Guerin, T.F. (1994). Constraints to the adoption of innovations in agricultural research and environmental management: a review, Australian Journal of Experimental Agriculture 34, 549-571.

Hagerstrand, T. (1967). Innovation diffusion as a spatial process, Chicago: The University of Chicago Press.

Havens, A.E. and Rogers, E.M. (1961). Adoption of hybrid corn: profitability and the interaction effect, Rural Sociology 26, 409-414.

Hawkins, H.S. and Watson, A.S. (1972). Shelford: a preliminary report of a social and economic study of a Victorian soldier settlement area, Melbourne: Agricultural Extension Research Unit, University of Melbourne.

Helms, G.L., Bailey, D. and Glover, T.F. (1987). Government programs and adoption of conservation tillage practices on nonirrigated wheat farms, American Journal of Agricultural Economics 69, 786-795.

Howden, P., and Vanclay, F. (2000). Mythologisation of farming styles in Australian broadacre cropping, Rural Sociology 65, 295-310.

Howden, P., Vanclay, F., Lemerle, D. and Kent, J. (1998). Working with the grain: farming styles amongst Australian broadacre croppers, Rural Society 8, 109-125.

Janis, M. and Mann, L. (1977). Decision making: a psychological analysis of conflict, choice and commitment, New York: Macmillan.

Kaine, G.W. and Lees, J.W. (1994). Patterns in innovation: An analysis of the adoption of practices in beef cattle breeding, Occasional paper no. 190, Armidale: Rural Development Centre, University of New England. 
Kaine, G., Bewsell, D., Boland, A. and Linehan, C. (2005). Using market research to understand the adoption of irrigation management strategies in the stone and pome fruit industry, Australian Journal of Experimental Agriculture 45, 1181-1187.

Kebede, Y. (1992). Risk behavior and new agricultural technologies: the case of producers in the central highlands of Ethiopia, Quarterly Journal of International Agriculture 31, 269-284.

Kilpatrick, S. (2000). Education and training: impacts on farm management practice, Journal of Agricultural Education and Extension 7, 105-116.

Kington, E.A. and Pannell, D.J. (2003). Dryland salinity in the upper Kent River catchment of Western Australia: Farmer perceptions and practices, Australian Journal of Experimental Agriculture 43, 19-28.

Kingwell, R.S., Pannell, D.J. and Robinson, S.D. (1993). Tactical responses to seasonal conditions in whole-farm planning in Western Australia, Agricultural Economics 8, 211-226.

Kingwell, R., Hajkowicz, S., Young, J., Patton, D., Trapnell, L., Edward, A., Krause, M. and Bathgate, A. (2003). Economic evaluation of salinity management options in cropping regions of Australia, Canberra: Grains Research and Development Corporation.

Knowles, M. (1984). The adult learner: a neglected species, Houston: Gulf Publishing Company.

Latta, J. (2002). A survey of farming practices in the low rainfall Mallee Regions of New South Wales, South Australia and Victoria, Walpeup: Department of Natural Resources and Environment.

Leathers, H.D. and Smale, M. (1992). A Bayesian approach to explaining sequential adoption of components of a technological package, American Journal of Agricultural Economics 68, 519-527.

Lindner, R.K. (1987). Adoption and diffusion of technology: an overview, in B.R. Champ, Highley, E. and Remenyi, J.V. (eds), Technological change in postharvest handling and transportation of grains in the humid tropics, ACIAR Proceedings No. 19, Canberra: Australian Centre for International Agricultural Research, pp. 144-151.

Lindner, R.K., Pardey, P.G. and Jarrett, F.G. (1982). Distance to information source and the time lag to early adoption of trace element fertilizers, Australian Journal of Agricultural Economics 26, 98-113.

Llewellyn, R.S. (2002). Adoption of integrated weed management by grain growers, $\mathrm{PhD}$ thesis, Perth: School of Agricultural and Resource Economics, University of Western Australia.

Llewellyn, R.S., Pannell, D.J., Lindner, R.K. and Powles, S.B. (2005). Targeting key perceptions when planning and evaluating extension, Australian Journal of Experimental Agriculture 45, 1627-1633.

Lockie, S., Mead, A., Vanclay, F. and Butler, B. (1995). Factors encouraging the adoption of more sustainable cropping systems in south-east Australia: profit, sustainability, risk and stability, Journal of Sustainable Agriculture 6, 61-79.

Lodge, G.M. (1991). Management practices and other factors contributing to the decline in persistence of grazed lucerne in temperate Australia: a review, Australian Journal of Experimental Agriculture 31, 713-724. 
Makeham, J.P. and Malcolm, L.R. (1993). The farming game now, Cambridge: Cambridge University Press.

Marra, M., Pannell, D.J. and Abadi Ghadim, A. (2003). The economics of risk, uncertainty and learning in the adoption of new agricultural technologies: where are we on the learning curve? Agricultural Systems 75, 215-234.

Marsh, S.P. (1998). What can agricultural researchers do to encourage the adoption of sustainable farming systems?, SEA Working paper 98/05, Perth: Agricultural and Resource Economics, University of Western Australia. Available at http://www.crcsalinity.com.au/ newsletter/SeaNews/dpap987f.htm (verified 21 September 2006).

Marsh, S.P. and Pannell, D.J. (2000). Agricultural extension policy in Australia: the good, the bad and the misguided, Australian Journal of Agricultural and Resource Economics 44, 605-627.

Marsh, S., Pannell, D. and Lindner, R. (2000). The impact of agricultural extension on adoption and diffusion of lupins as a new crop in Western Australia, Australian Journal of Experimental Agriculture 40, 571-583.

Marsh, S.P., Burton, M.P. and Pannell, D.J. (2006). Understanding farmers' monitoring of water tables for salinity management, Australian Journal of Experimental Agriculture 46, 1113-1122.

Marshall, G.R. (2004a). From words to deeds: enforcing farmers' conservation costsharing commitments, Journal of Rural Studies 20, 157-167.

Marshall, G.R. (2004b). Farmers cooperating in the commons? A study of collective action in salinity management, Ecological Economics 51, 271-286.

Marshall, G.R. (2005). Economics for collaborative environmental management: renegotiating the commons, London: Earthscan Publications.

Mesiti, L. and Vanclay, F. (2006). Specifying the farming styles in viticulture, Australian Journal of Experimental Agriculture 46, 585-593.

Miranowski, J.A. and Carlson, G.A. (1993). Agricultural resource economics: an overview, in Carlson, G.A., Zilberman, D. and Miranowski, J.A. (eds), Agricultural and environmental resource economics, New York: Oxford University Press, pp. 3-27.

Miranowski, J.A., Hrubovak, J. and Sutton, J. (1991). The effects of commodity programs on resource use, in Bockstael, N. and Just, R. (eds), Commodity and resource policies in agricultural systems, New York: Springer-Verlag, pp. 275292.

Mues, C., Chapman, L. and Van Hilst, R. (1998). Survey of Landcare and land management practices: 1992-93, Canberra: Australian Bureau of Agricultural and Resource Economics.

Mullen, J.D., Vernon, D. and Fishpool, K.I. (2000). Agricultural extension policy in Australia: public funding and market failure, Australian Journal of Agricultural and Resource Economics 44, 629-645.

Nicoll, R. (1994). Landholders' knowledge and perceptions of dryland salinity control options in the Broadford and Kilmore shires, Melbourne: Environmental Management Research Project, Deakin University.

Ohlmer, B., Olson, K. and Brehmer, B. (1998). Understanding farmers' decision making processes and improving managerial assistance, Journal of Agricultural Economics 18, 273-290. 
Ostrom, E. (1998). A behavioral approach to the rational choice theory of collective action, American Political Science Review 92, 1-22.

Ostrom, E., Gardner, R. and Walker, J. (1994). Regularities from the laboratory and possible explanations, in E. Ostrom, R. Gardner and Walker, J. (eds), Rules, games, and common-pool resources, Ann Arbor: University of Michigan Press, pp. 195-220.

Pannell, D.J. (1996). Lessons from a decade of whole-farm modelling in Western Australia, Review of Agricultural Economics 18, 373-383.

Pannell, D.J. (1999). Social and economic challenges in the development of complex farming systems, Agroforestry Systems 45, 395-409.

Pannell, D.J. (2001a). Dryland salinity: economic, scientific, social and policy dimensions, The Australian Journal of Agricultural and Resource Economics 45, 517-546.

Pannell, D.J. (2001b). Explaining non-adoption of practices to prevent dryland salinity in Western Australia: implications for policy, in Conacher, A. (ed), Land degradation, Dordrecht: Kluwer, pp. 335-346.

Pannell, D.J., McFarlane, D.J. and Ferdowsian, R. (2001). Rethinking the externality issue for dryland salinity in Western Australia, Australian Journal of Agricultural and Resource Economics 45, 459-475.

Phillips, T.I. (1985). The development of methodologies for the determination and facilitation of learning for dairy farmers, Master's thesis, Melbourne: School of Agriculture and Forestry, University of Melbourne.

Presser, H.A. and Cornish, J.B. (1968). Channels of information and farmers' goals in relation to the adoption of recommended practices: a survey in a dried fruit growing district, Melbourne: University of Melbourne, School of Agriculture.

Rahm, M.R. and Huffman, W.E. (1984). The adoption of reduced tillage: the role of human capital and other variables, American Journal of Agricultural Economics 66, 405-412.

Ransom, K. and Barr, N. (1994). The adoption of dryland lucerne in northcentral Victoria, Research Report Series No. 151, Melbourne: Department of Agriculture.

Reeve, I. (2001). Australian farmers' attitudes on rural environmental issues: 19912000, Report to Land and Water Australia, Armidale: Institute for Rural Futures, University of New England.

Reeve, I, Frost, L., Musgrave, W. and Stayner, R. (2002). Agriculture and natural resource management in the Murray Darling Basin: policy history and analysis, Report to the Murray Darling Basin Commission, Armidale: Institute for Rural Futures, University of New England.

Ridley, A.M. and Pannell, D.J. (2005). The role of plants and plant-based R\&D in managing dryland salinity in Australia, Australian Journal of Experimental Agriculture 45, 1341-1355.

Rogers, E.M. (1962). Diffusion of innovations, New York: Free Press.

Rogers, E.M. (2003). Diffusion of innovations, 5th ed., New York: Free Press.

Röling, N.G. (1988). Extension science, information systems in agricultural development, Cambridge: Cambridge University Press.

Ruttan, V.W. (1996). What happened to technology adoption-diffusion research?, Sociologia Ruralis 36, 51-73. 
Shampine, A. (1998). Compensating for information externalities in technology diffusion models, American Journal of Agricultural Economics 80, 337-346.

Shapiro, B.I., Brorsen, B.W. and Doster, D.H. (1992). Adoption of doublecropping soyabean and wheat, Southern Journal of Agricultural Economics 24, 33-40.

Shrapnel, M. (2002). Bushies and cockies - beyond the myths: the personalities of our outback land managers, Master's thesis, Brisbane: University of Queensland.

Shrapnel, M. and Davie, J. (2001). The influence of personality in determining farmer responsiveness to risk, Journal of Agricultural Education and Extension 7, $167-178$.

Sinden, J.A. and King, D.A. (1990). Adoption of soil conservation measures in Manilla Shire, New South Wales, Review of Marketing and Agricultural Economics 58, 179-192.

Sobels, J., Curtis, A. and Lockie, S. (2001). The role of Landcare networks in rural Australia: exploring the contribution of social capital, Journal of Rural Studies 17, 265-276.

Stoyles, M. (1992). Cultural barriers to extension: results of a survey of the non English speaking background farmers in east Shepparton, Melbourne: Ethnic Communications.

Tonks, I. (1983). Bayesian learning and the optimal investment decision of the firm, Economic Journal 93, 87-98.

Tsur, Y., Sternberg, M. and Hochman, E. (1990). Dynamic modelling of innovation process adoption with risk aversion and learning, Oxford Economic Papers 42, 336-355.

Vanclay, F. (1986). Socio-economic correlates of adoption of soil conservation technology, Master's thesis, Brisbane: Department of Anthropology and Sociology, University of Queensland.

Vanclay, F. (1992). The social context of farmers' adoption of environmentally sound farming practices, in Vanclay, F. and Furze, B. (eds), Agriculture, environment and society: contemporary issues for Australia, Melbourne: Macmillan, pp. 94-121.

Vanclay, F. (1997). The social basis of environmental management, in Lockie, S. and Vanclay, F. (eds), Critical landcare, Centre for Rural Social Research, Wagga Wagga: Charles Sturt University, pp. 9-27.

Vanclay, F. (2002). Conceptualising social impacts, Environmental Impact Assessment Review 22, 183-211.

Vanclay, F. (2004). Social principles for agricultural extension to assist in the promotion of natural resource management, Australian Journal of Experimental Agriculture 44, 213-222.

Vanclay, F. and Lawrence, G. (1995). The environmental imperative, Rockhampton: Central Queensland University Press.

Vanclay, F. and Lockie, S. (1993). Barriers to the adoption of sustainable crop rotations, Wagga Wagga: Centre for Rural Social Research, Charles Sturt University.

Vanclay, F., Mesiti, L. and Howden, P. (1998). Styles of farming and farming subcultures: Appropriate concepts for Australian rural sociology?, Rural Society 8 , 85-107. 
Vanclay, F., Howden, P., Mesiti, L. and Glyde, S. (2006). The social and intellectual construction of farming styles, Sociologia Ruralis 46, 61-82.

Weston, R.E. and Cary, J.W. (1979). A change for the better: stress, attitudes and decision making of dairy farmers 1976 to 1978, Melbourne: School of Agriculture and Forestry, University of Melbourne.

Wiebers, U.C. (1992). Economic and environmental effects of pest management information and pesticides: the case of processing tomatoes in California, $\mathrm{PhD}$ thesis, Berlin: Technical University of Berlin.

Wilkinson, R.L. (1989). Stepwise adoption of a complex agricultural technology, Master's thesis, Melbourne: University of Melbourne.

Wilkinson, R. and Cary, J.W. (1992). Monitoring landcare in north central Victoria, Melbourne: School of Agriculture and Forestry, University of Melbourne.

Wilkinson, R.L. and Cary, J.W. (1993). Monitoring soilcare in north east Victoria, Melbourne, School of Agriculture and Forestry, University of Melbourne. 